\title{
Human resources in the context of digitalization of agriculture
}

\author{
Milyausha S. Faskhutdinova ${ }^{1}$, Elmira F. Amirova ${ }^{2}$, Ilnur N. Safiullin ${ }^{2}$, and Linar G. Ibragimov ${ }^{1}$ \\ ${ }^{1}$ Kazan branch of Russian State University of Justice, 420088 Kazan, Russia \\ ${ }^{2}$ Kazan State Agrarian University, 420015 Kazan, Russia
}

\begin{abstract}
The article discusses the concept of digitalization of agriculture which should significantly change the face of the industry. In addition to increasing production efficiency and revenues, the authors propose attracting new employees and creating high-tech industries. Over time, this will allow establishing interaction with digitalization programs in other sectors, in particular with logistics, and creating platforms to support such integrated digital solutions that will popularize domestic products actively introduced into agriculture. One of the significant challenges facing implementation is its substantial demand for staff with relevant digital knowledge. Moreover, if financial injections help remove technical and technological obstacles to digitalization, then staffing the expected changes, especially on the planned scale, will require not only material support but also active organizational and methodological work. The international component may be the most important aspect of upgrading agricultural education in Russia. Over the past decade, some steps have been taken to meaningfully modernize vocational education, improve its quality and integrate Russian education into the international educational space. Despite the undeniable benefits, farmers are faced with the problems of integrating new systems into existing business processes, the lack of a comprehensive solution to their automation, the lack of staff competent in modern IT technologies. Addressing these issues will enable the transition of agriculture to the digital economy at an accelerated pace.
\end{abstract}

\section{Introduction}

The digitalization of agriculture is necessary to improve the efficiency and sustainability of its functioning through fundamental changes in the quality of management of both technological and decision-making processes at all levels of the hierarchy based on modern methods of production and further use of state information and forecasting possible changes in managed elements and subsystems, as well as economic conditions in agriculture.

Measures on digitalization of agriculture in Russia make it possible to achieve following goals: a technological breakthrough in the agro-industrial complex and a significant increase in labour productivity at digital agricultural enterprises using modern automation, computerization technologies at all stages of agricultural production and processing; transformation of public administration processes in the field of agriculture and ensuring the efficiency and effectiveness of decisions based on the formation of a single information space using modern digital technologies that ensure the completeness and consistency of information in the framework of state land monitoring, land supervision, territorial planning, federal property accounting, cadastral registration data and data on registered land rights.

\section{Materials and methods}

One of the key indicators is Personnel for the digital economy, the annual number of graduates of state higher education institutions. It is estimated that by 2024 this figure should reach 120,000 people a year.

Also, large-scale digitalization of all industries and fields requires all employees of enterprises and organizations to master the basic competencies of the digital economy. It is assumed that it should include at least 800,000 people a year to meet the needs of the economy for graduates in other fields who have digital competencies at the level not lower than the global average. Besides, at least $40 \%$ of the working-age adult population must have digital skills.

The federal project Personnel for the Digital Economy provides a wide range of measures of a very different nature to be implemented both at the federal and regional levels (Table 1).

Assistance to citizens in the development of digital literacy and the competencies of the digital economy involves the creation of a public free online service for the development of digital literacy, as well as the state system of personal digital certificates for the development of competencies in the digital economy. However, more than 10 million people (including at least 270,000 working professionals, among them heads of organizations and representatives of the executive branch) are expected to be trained in online digital literacy programmes from 2019. At least 1 million

Corresponding author: Violamila@mail.ru 
people will receive personal digital certificates while training in digital economy competencies [4].

Table 1. The main tasks in the framework of implementing the Federal project Personnel for the digital economy

\begin{tabular}{|c|l|}
\hline Direction & \multicolumn{1}{|c|}{ Tasks within the direction } \\
\hline $\begin{array}{c}\text { Ensuring the } \\
\text { training of highly } \\
\text { qualified personnel } \\
\text { for the digital } \\
\text { economy }\end{array}$ & $\begin{array}{l}\text { - development of a core competency } \\
\text { model for the digital economy } \\
\text { - creation of a venture capital fund to } \\
\text { technologies in the digital economy } \\
\text { - allocation of grants and subsidies for } \\
\text { the creation and support of continuing } \\
\text { - development of digital educational and } \\
\text { methodological complexes, training } \\
\text { simulators, virtual laboratories for the } \\
\text { implementation of educational programs }\end{array}$ \\
$\begin{array}{c}\text { Developing } \\
\text { educational }\end{array}$ & $\begin{array}{l}\text { - creation of a public free online service } \\
\text { for the development of digital literacy } \\
\text { - updating of federal state educational } \\
\text { programs for the } \\
\text { dissemination of } \\
\text { digital }\end{array}$ \\
$\begin{array}{l}\text { the formation of digital economy } \\
\text { competencies } \\
\text { - creation of a digital service providing } \\
\text { the formation of a personal profile of } \\
\text { competencies }\end{array}$ \\
\hline
\end{tabular}

Developed countries are successfully modernizing their economies, developing innovative technologies at an accelerated pace, dominated by artificial intelligence, automation and digital platforms. By 2021, experts predict that $25 \%$ of the world's economy will shift to digital technologies that will allow the state, business, and society to function effectively.

The Order of the Government of the Russian Federation of July 28, 2017, No. 1632-r approved the State Program Digital Economy of the Russian Federation wich states "... digital data is a key factor in production in all areas of socio-economic activity, which increases the country's competitiveness and quality life of citizens, provides economic growth and national sovereignty" [10].

In agriculture of the last decade, the use of photographic control systems, integrated machine control, precision farming is the industry standard. However, the level of digital adoption in agriculture remains low. The world leaders in digital implementation are IT companies, media, finance and insurance.

The domestic agricultural industry faced with the task of increasing labour productivity and competitiveness through the application of the latest scientific achievements and best practices.

First, we are talking about Russia's entry into the Bologna process, increasing the flexibility of educational programs, overcoming the early narrow specialization, introducing federal state educational standards for vocational education. Domestic educational institutions should not be passive but active participants in the internationalization of education, increase the export of educational services, build a balanced system of relations with foreign partners that would reflect the interests of Russia.

We should remember that, historically, Russia has always been an agrarian country, and its prosperity was largely dependent on the effective development of agriculture. The main task of developing the country as the world's largest state is the arrangement of territories in which agricultural education plays a key role. At the beginning of the XXI century, when the Russian agroindustrial complex entered a new period of its development, the qualifications and competence of specialists largely depend on solving the country's food security issues, preserving and reviving the Russian countryside.

For a long time, agriculture was not a business attractive to investors, due to the long production cycle, prone to natural risks and high crop losses during cultivation, harvesting and storage, inability to automate biological processes and lack of progress in improving productivity and innovation.

The transition to a digital economy requires a revision of the human resources management paradigm. It was reflected in the Digital Economy program approved at the end of July 2017, which defines the goals and objectives of the new economic system until 2025.

In the context of the priority areas of the Personnel and Education concept, the state sets the main goal, the essence of which is to solve the problem of training, retraining and further training of personnel by 2025 .

This work will improve the level of professionalism, competence, experience, loyalty and dedication of employees of various enterprises which is necessary for the digital economy system in our country. In the era of the digital economy, conceptual knowledge comes to the fore.

They are a strategically important asset to ensure the competitiveness and financial stability of the enterprise. For this reason, it is necessary to create and improve conceptual approaches to the design and implementation of human resources development strategies based on modern methods and appropriate tools, and integrate corporate knowledge into the company's management system.

The main challenges for education, the economy and society in the context of the digital economy include training relevant personnel, developing modern competency requirements and universal digital literacy.

This leads to the following objectives:

- training of highly qualified personnel in the direction and development of the digital segment of the economy;

- elimination of digital illiteracy of all categories of personnel of modern enterprises, organizations and institutions;

- continuous formation of digital culture among citizens of the country;

- gradual replacement of obsolete documents, such as an employment record book, diploma, etc.

In Russia, the current number of specialists in the field of information systems and technologies is approximately $1.5 \%$ of the total working staff. In the 
highly developed countries of Europe, this parameter varies from about 3 to $5 \%$.

This is confirmed by the fact that enterprises and organizations of all forms of ownership of the country lack highly qualified specialists in this field.

The education system should adapt to constantly changing environmental requirements and shift the focus in educational programs from the development of exclusively subject knowledge and remembering rapidly ageing information to the development, first, of personal and meta-subject competencies which will be more and more demanded [14].

The use of IT in agriculture included the use of computers and software mainly for financial management and tracking business transactions. However, farmers began to use digital technology to monitor crops, livestock, and various elements of the agricultural process.

\section{Results}

Technologies evolved, and a sharp jump in the segment occurred when technology companies turned their attention to agriculture who learned together with partners to control the full crops or livestock cycle through smart devices that transmit and finish the current parameters of each object and its environment (equipment and sensors that measure parameters of soil, plants, microclimate, animal characteristics, etc.), as well as seamless communication channels between them and external partners.

Due to the integration of objects into a single network, the exchange and management of data based on the Internet of things, the increased production capacity of computers, the development of software and cloud platforms, it became possible to automate the maximum number of agricultural processes by creating a virtual (digital) model of the entire production cycle and interconnected chain links value creation, and with mathematical precision to plan a work schedule, take emergency measures to prevent losses in unrecorded threats and, to calculate the possible yield, production costs and profits.

Control is as follows: the field monitoring process consists of three blocks, such as data collection, analysis and decision-making. The use of sensors, operational monitoring and monitoring from space makes it possible to collect information on field properties, the environment, harmful objects, the state of transport, the use of resources and crop development. Sensors transmit information received from agricultural machinery to Cropio software, weather stations, a control centre and drones operate to solve certain problems. All fields are $100 \%$ digitized in the GIS, which allows controlling the progress of geolocation operations.

The catalyst in evolution and progress is a set of technologies united by the common name of the Internet of things. This is a combination of fundamental achievements in the data analysis (Data Science, artificial intelligence, machine learning), innovative achievements in the development of sensors and self- propelled (unmanned) technologies that collect and monitor data at all levels not previously accessible, as well as they are connected with network solutions, management systems, platforms and applications that bring plants and animals to the next level.

Agriculture is becoming a sector with a very intensive data flow. Information comes from various devices located in the field, on the farm, from sensors, agricultural machinery, weather stations, drones, satellites, external systems, partner platforms, and suppliers.

The general data of various participants in the production chain collected in one place allows receiving new quality information, find samples, create additional value for all involved participants, apply modern scientific processing methods (scientific data) and make the right decisions that minimize risks based on them, improve manufacturers business and customer experience.

Mobile or online applications become available for farmers, agronomists, consultants who download data about their field (coordinates, areas, type of crops, past crops) and give accurate recommendations and a sequence of actions based on the analysis of much historical data and current factors, like in their field and the external environment, combining data on technology, sensors, drones, satellite and other external programs.

Now the program helps to determine the best time for planting seeds, fertilizing, moisturizing or collecting, to calculate the time of loading and delivery of goods to the buyer, to monitor the temperature in the storage and transportation zone and avoid spoilage and delivery of fresh products, to predict crop and income and get tips on improving plant processing compared to past performance.

To solve such problems, we propose the implementation of DIGITAL-analysis at agricultural enterprises [6].

1. The purpose of the digital analysis. The purpose is to assess the readiness of agricultural organizations for modernization in the digital economy.

2. The tasks of digital analysis. The main tasks include:

- development of information for management decision-making on the prospects and readiness of the transition of individual business entities to the systematic use of digital technologies;

- data collection for the development of regional agricultural modernization programs;

- scoring of deficits and problematic aspects that impede the digitalization of agricultural production;

- quantitative internal assessment of promising areas in digitalization of agricultural production;

- assessment of the state of technological and innovative processes in the industry and directions for their further development;

- identification of technological barriers that impede the development of the agricultural sector of the economy (Table 2).

Along with the concept Digital Economy, there is a new concept Digital Farming which describes the 
evolution of agriculture and agricultural technology from precision farming to agricultural production systems based on modern knowledge. Digital farming uses Precision Farming technology, and it also uses smart networks and data management tools.

Table 2. Characterization of the analytical blocks of the DIGITAL-analysis

\begin{tabular}{|l|l|}
\hline Analytical blocks & Characteristics of analytical blocks \\
\hline Deficits & $\begin{array}{l}\text { It reflects the needs for elements of } \\
\text { modernization transformations of a } \\
\text { digital nature, satisfying the emerging } \\
\text { and recognized production, } \\
\text { technological, resource and } \\
\text { organizational-economic deficits }\end{array}$ \\
\hline $\begin{array}{l}\text { Innovations in } \\
\text { agriculture }\end{array}$ & $\begin{array}{l}\text { It establishes the degree of innovative } \\
\text { activity of agriculture, determining the } \\
\text { results of research activities developed } \\
\text { and ready for implementation in smart } \\
\text { agriculture, breeding, genomics, } \\
\text { urbanized farms, etc. }\end{array}$ \\
\hline $\begin{array}{l}\text { Land resources } \\
\text { and climate }\end{array}$ & $\begin{array}{l}\text { It analyzes the state of bioresources in } \\
\text { general and land resources in particular, } \\
\text { as the main objects of digital technology }\end{array}$ \\
\hline Infrastructure & $\begin{array}{l}\text { It reflects the degree and features of the } \\
\text { development of a network of specialized } \\
\text { infrastructure facilities that develop, } \\
\text { implement and accompany innovative } \\
\text { digital developments and technologies }\end{array}$ \\
\hline $\begin{array}{l}\text { Equipment and } \\
\text { technologies }\end{array}$ & $\begin{array}{l}\text { It assesses the availability and } \\
\text { sufficiency of technical means and } \\
\text { technologies for the implementation of } \\
\text { the concept of digital agricultural } \\
\text { economics. }\end{array}$ \\
\hline pystem & $\begin{array}{l}\text { It evaluates the effectiveness of the } \\
\text { management decision-making system } \\
\text { both in general and in business } \\
\text { processes }\end{array}$ \\
\hline $\begin{array}{l}\text { It assesses the regulatory and } \\
\text { institutional conditions for consolidating } \\
\text { the legislative status and legitimization } \\
\text { of digital technologies in the } \\
\text { manufacturing sector and public life. }\end{array}$ \\
\hline
\end{tabular}

The purpose of digital agriculture is to use all available knowledge and experience to automate agricultural processes. The purpose of precision farming is to reduce costs by providing each plant with what they need for optimal growth, producing more products with fewer products.

In the early 2010s, the possibilities of precision farming were expanded with the advent of new technologies such as cheap and improved sensors and microprocessors, high-speed cellular communications, cloud systems and big data analysis. As a result, data no longer comes from used agricultural equipment, but also from new services with new algorithms to turn data into efficient intelligence.

Digital farming is similar in structure to the already used concept of Industry 4.0. However, technological processes of agricultural production are somewhat different from industrial processes, since agriculture is largely determined by natural and biological factors, so the term Digital Agriculture appeared [13].
The scope of digital agriculture covers all aspects of agriculture, primary production in crop production and animal husbandry. Farmers and agricultural contractors will be the primary producers, then the final consumer follows.

Due to the complexity of agricultural production processes in digital agriculture, there are many relevant business partners and various sources of information, broad and differentiated communication structures.

There must be two basic conditions for digital agriculture to become a reality. Firstly, it is intelligent machines, machines should be able to receive, send, produce (via sensors) and process data. Secondly, it is connected machines, communication and interface standards should provide unhindered data exchange between machines, partners and portals.

For example, Variable Speed Technology (VRT) based on soil sampling, was initially limited to soil sampling, analysis and compilation of electronic NPK nutrient distribution maps, and was significantly improved with field variability data. It is obtained using yield monitors.

The next step is to improve task maps for differentiated fertilizer application using algorithms based on data from several fields and considering parameters not directly related to the field itself, such as seed characteristics and environmental conditions.

Digital agriculture offers new opportunities for operational management by improving production processes through automatic data collection and targeted analysis to increase transparency and assess the current situation. For data processing, and especially for analysis, there are expert systems that are difficult or impossible to achieve for individual farms through internal data processing by end-users.

The task of training personnel for the needs of the digital economy is not only to increase the efficiency of using the existing scientific and educational potential but also to increase it, on the one hand, the need to constantly update the content of the disciplines related to digital competencies due to the rapid obsolescence of technologies in this direction, and on the other hand, it sets itself the task of organizing the graduation of specialists in completely new educational ways as quickly as possible which cannot be done without creating own scientific and methodological base of the crane in the digital economy.

By the way, the Ministry of Agriculture of Tatarstan was one of the first in Russia to rely on tomorrow's technology, and also acted as one of the initiators of the inclusion of the agricultural sector in the federal program Digital Economy of the Russian Federation.

A year ago, a corresponding subprogram was developed in the republic that gave impetus to the digital transformation of the industry. Work is already underway in areas such as information-analytical and geographic information systems of the agro-industrial complex, a single window for applying for subsidies, various digital solutions at the level of agricultural enterprises, and training of IT specialists [3]. 


\section{Conclusion}

Human resources are key to everything. Only an educated and competent agricultural producer can understand and see that the introduction of new technologies results in saving, the analytical systems help to make better management decisions, to buy the equipment that does not turn into a dusty toy in the warehouse but benefits every day [12].

Unfortunately, we often find that push-button telephones and calculators, pencils and notebooks are still in use. Today, many farm owners and agronomists do not understand why they need to change the way they work, and the young generation coming from the university to work does not have practical skills to use modern technologies, unfortunately, and demonstrates the problems of the modern system of Russian education because generally, they do not have domain knowledge.

External consultants, often IT specialists, although they understand how to digitize a company and how to apply new technologies, are still usually affiliated with some manufacturer and therefore are interested in promoting their products rather than solving the farmer's pressing problems.

\section{Recommendations}

The rapid spread of digital technologies, their deep penetration into all spheres of life, a strong and comprehensive impact on socio-economic development, the unprecedented scale of the changes they entail, as well as the uncertainty with the possible consequences of this process, attract the attention of researchers and specialists in government and business community.

Against the backdrop of intense competition of foreign food producers and the global agricultural crisis caused, among other things, by climate change on the planet, environmental problems and economic imbalances, the transfer of the country's agriculture to new technologies is the most important tool for maintaining the growth rate of the domestic agricultural industry and ensuring reliable export prospects for the Russian agricultural sector [3].

Summing up the general result, we should say that the digitalization of the economy is a global process, independent of the economic, political, social and other difficulties of each country. Its influence requires certain changes in any country. The success of the digitization of the Russian economy will depend on the availability of qualified specialists and a radical change in the mentality of managers [5].

The main problems hindering the rapid digitalization of agriculture include:

- shortage of highly qualified IT specialists in the industry;

- poor development of digital infrastructure in rural areas;

- insufficient financial resources to implement modern info-communication technologies in rural areas;

- high percentage of digital illiteracy in rural areas;
- lack of legal regulation of using infocommunication technologies in the agricultural sector.

Key opportunities for the digital transformation of agriculture include:

- creation of digital methods and technical tools for monitoring fields, compiling soil maps (using remote sensing of the earth);

- development of systems for the analysis and forecasting of yields associated with geographic information systems;

- development of technologies and technical tools for agricultural robotics (smart harvesters, etc.);

- development of a digital platform for managing the agro-industrial complex.

Training highly qualified specialists in new and traditional areas is a priority in staffing for the digitalization of agriculture. We propose the following solutions:

- training of young specialists for work through the master's degree programmes of selected higher education institutions in the country, including basic higher education institutions for the staff training for enterprises in the sector;

- training of young specialists in new areas;

- the direction of personnel for retraining in the leading higher education institutions of the country with an orientation to gaining knowledge in the field of management that will make it possible to use the high scientific potential of training in solving the most important problems of the development of the industry.

\section{References}

1. A.G. Arkhipov, S.N. Kosogor, O.A. Motorin et al., Digital Transformation of Russian Agriculture: (Rosinformagroteh, Moscow, 2019), 80 p.

2. E.F. Amirova, The functioning of the grain product subcomplex in the conditions of the food embargo, Bull. of Kazan State Agrar. Univer., 13(1(48)), 147-151 (2018)

3. AIC of the future: total digitalization. Retrieved from: https://yandex.ru/turbo

4. N.V. Kuznetsov, V.V. Lizyaeva, T.A. Prokhorova, Yu.G. Lesnykh, Staff training for the implementation of the national program "Digital Economy of the Russian Federation”, Modern probl. of sci. and ed., 1 (2020)

5. Sh.Z. Mehdiev, Formation of a qualified personnel system in the digital economy, Herald of the Eurasian Sci., 6 (2018). Retrieved from: https://esj.today/PDF/17ECVN618.pdf

6. I.B. Manzhosova, DIGITAL-analysis methodology for assessing transformation processes in agriculture during the transition to the digital economy, text of a scientific article in the specialty "Economics and Business", Moscow Econ. J., 3, 123

7. National Congress. Modernization of Russian industry: development priorities, Agriculture in 
digital format. Retrieved from: http://2050.digital/news/press-reliz/

8. A.N. Semin, Strengthening human resources in the agricultural sector of Russia, Econ. of agricult. and proce. Enterpr., 10, 9-11 (2011)

9. M.S. Faskhutdinova, A.R. Nurtdinov, The introduction of budgeting in the context of building a digital economy in agricultural enterprises, Sci. Rev.: Theory and Pract., 1, 51-62 (2020)

10. By an order of the Government of the Russian Federation dated 28 July 2017, no. 1632-r, the State program "Digital Economy of the Russian Federation" was approved

11. Official site of IT-Business CRN, J'son \& Partners Consulting. Retrieved from:
12. The official website of Direct.Farm of Krasnodar Region. Retrieved from: https://direct.farm/post

13. The official website of SvetichAgromedia Holding. Digital farming. Retrieved from: http://svetich.info/publikacii/tochnoe-zemledelie/cifrovoezemledelie-digital-farming.html

14. The human resources departments have undergone a digital revolution. Retrieved from: https://www.vedomosti.ru/.

15. The program for the development of the digital economy in the Russian Federation until 2035. Retrieved from: http://spkurdyumov.ru/uploads/ 2017/05 / strategy.pdf. 